\title{
Sonografie in der Frühschwangerschaft
}

\section{DEGUM-Experten: Nichtinvasive Pränataltests nur mit zusätzlicher Ultraschalluntersuchung}

Wird mein Kind gesund zur Welt kommen? Hat es Fehlbildungen oder angeborene Erkrankungen? Dies sind zentrale Fragen, die werdende Eltern umtreiben. Auskunft erhoffen sich viele nicht nur von den Ultraschalluntersuchungen, sondern auch von den in Deutschland seit 2012 angebotenen Screeningtests, bei denen das Blutplasma der Schwangeren auf Trisomien und die Geschlechtschromosomen untersucht wird. Der Gemeinsame Bundesausschuss (G-BA) hat vor Kurzem vorgeschlagen, dass diese künftig für Risikoschwangere zur Kassenleistung werden sollen. Experten der Deutschen Gesellschaft für Ultraschall in der Medizin e. V. (DEGUM) machen darauf aufmerksam, dass eine differenzierte sonografische Untersuchung vor dem Test stattfinden muss. Warum diese so relevant ist und welche weiteren pränataldiagnostischen Untersuchungen in der Frühschwangerschaft empfehlenswert sind, erläutern sie auf einer Pressekonferenz in Berlin, die Ende April stattgefunden hat.

Die sogenannten nichtinvasiven Pränataltests (NIPT) ermöglichen ein zielgerichtetes Screening auf die Trisomien 21 (Down-Syndrom), 13 (Pätau-Syndrom) und 18 (Edwards-Syndrom) sowie auf die Anzahl der Geschlechtschromosomen. Mithilfe dieser Tests untersuchen Mediziner das Blutplasma der Schwangeren, in dem sich nicht nur Teilstücke deren eigenen Erbmaterials befinden, sondern bis zu 10 Prozent zellfreie DNA der Plazenta. Der Gemeinsame Bundesausschuss (G-BA) hat im März dieses Jahres vorgeschlagen, dass solche Tests bei Schwangeren mit besonderen Risiken zur Kassenleistung werden sollen. „Allerdings ist es sehr wichtig, dass eine differenzierte
Ultraschalluntersuchung noch vor dem DNA-Test stattfindet“, betont Professor Dr. Peter Kozlowski, Vorstandsmitglied der Deutschen Gesellschaft für Ultraschall in der Medizin e. V. (DEGUM). „Wir beobachten in der pränataldiagnostischen Beratung, dass ein unauffälliger Befund eines DNA-Screenings auf Trisomie mit einem gesunden Kind gleichgesetzt wird. Der Verzicht auf eine frühzeitige differenzierte Ultraschalluntersuchung kann auch zur Folge haben, dass Fehlbildungen des Ungeborenen erst spät entdeckt werden“, so der Düsseldorfer Pränatalmediziner weiter.

Gerade der DNA-Test birgt die Gefahr, dass neben falsch negativen auch falsch positive Testergebnisse vorliegen können. „Das kann die werdenden Eltern unnötig in große Besorgnis stürzen oder in falscher Sicherheit wiegen“, sagt Professor Kozlowski. Nach einem positiven Screening-Befund im Ultraschall oder durch Bluttests sei deshalb eine Absicherung durch diagnostische Punktion unabdingbar. „Wichtig zu wissen ist vor allem, dass der DNA-Bluttest keine Alternative zur frühen Ultraschallfeindiagnostik und zum Serumscreening ist, sondern vielmehr eine zusätzliche Untersuchung darstellt.“

Die frühe Ultraschallfeindiagnostik - elementarer Teil des sogenannten ErsttrimesterScreenings - gehört zu den schonenden, nichtinvasiven Methoden der Pränataldiagnostik. Das Screening kann zwischen Anfang der 12. und Ende der 14. Schwangerschaftswoche durchgeführt werden und besteht aus einer möglichst differenzierten Untersuchung des Ungeborenen sowie einem Bluttest bei der Schwangeren. „Mehr als die Hälfte relevanter fetaler Fehlbildungen kann dabei frühzeitig erkannt werden“, erklärt Professor Kozlowski. Die Untersuchung ist bisher nicht
Bestandteil der Routinevorsorge in der Schwangerschaft und muss deshalb selbst finanziert werden. „Es wird dennoch von einer großen Anzahl von Frauen in Anspruch genommen“, so Professor Kozlowski. Das Ersttrimester-Screening sei in allen mütterlichen Altersgruppen sinnvoll und empfehlenswert, da es nicht auf Erkennung der Trisomien 21, 13 und 18 fokussiert ist. Besonders bei jungen Frauen überwiegen andere genetische $\mathrm{Er}$ krankungen des Fötus. Auch Frauen mit problematischeren Schwangerschaftsverläufen rät der Experte zu solchen Untersuchungen.

Mithilfe des feindiagnostischen Ultraschalls werden die Organe des Ungeborenen untersucht sowie die Breite der Gewebeflüssigkeit im Nackenbereich gemessen. Eine verdickte Nackentransparenz kann auf verschiedene Chromosomen-Abweichungen oder auch auf einen Herzfehler hindeuten.

Im Blut der Schwangeren werden bestimmte Hormon- und Eiweißwerte bestimmt: Zum einen wird das Hormon hCG (humanes Choriongonadotropin) gemessen. Ein erhöhter hCG-Wert kann auf eine Chromosomen-Störung beim Ungeborenen hinweisen. Hinzu kommt die Messung des Eiweißes PAPP-A (pregnancy-associated plasma protein A) und des Wachstumsfaktors PLGF in der Plazenta. Ein niedriger PAPP-A-Wert kann ebenfalls ein Hinweis auf eine Chromosomen-Abweichung sein. „Aus den Werten PAPP-A und PLGF sowie durch Messungen der Blutversorgung der Plazenta und des mütterlichen Blutflusses können zudem die Risiken für Präeklampsie und für Wachstumsstörungen des Ungeborenen bestimmt werden“, erklärt Professor Kozlowski. Präeklampsie ist eine Komplikation im Verlauf der Schwangerschaft, die sich durch Bluthochdruck, Wassereinlagerungen im Gewebe und Ei- 
weißausscheidungen im Urin bei der werdenden Mutter äußert. Das ungeborene Kind kann durch eine Präeklampsie von einer Unterfunktion der Plazenta betroffen sein.

„Wenn erforderlich, kann dann mittels der frühzeitigen Gabe von Aspirin der weitere
Verlauf zahlreicher Schwangerschaften positiv beeinflusst werden."

Die 3 Ultraschall-Basisuntersuchungen als Bestandteil der Routinevorsorge und die aufgeführten zusätzlichen Screening-Leistungen wie Nackentransparenzmessung,
Blutuntersuchung und Blutdurchflussmessung ergeben zusammen ein gutes Gesamtbild der pränatalen Vorsorge. „Dabei bildet der Ultraschall die Basis“, sagt Professor Kozlowski, „und ist zum Beispiel auch für die Frauen wichtig, die das Risiko genetischer Störungen nicht erfahren wollen.“ 